\title{
UTICAJ AERODROMSKIH TEHNOLOŠKIH REŠENJA NA ZADOVOLJSTVO PUTNIKA: AERODROM "NIKOLA TESLA"
}

\author{
Jelena Vukelić, \\ Angelina Njeguš*, \\ Radmila Živković, \\ Milica Čolović
}

Univerzitet Singidunum, Beograd, Srbija

Odgovorno lice:

Angelina Njeguš

e-pošta:

anjegus@singidunum.ac.rs

\begin{abstract}
Rezime:
Avio industrija je najdinamičnija komponenta turističke industrije, koja je pionir u primeni najsavremenijih tehnoloških rešenja. Jedna od ključnih metrika za ocenu performansi tehnoloških rešenja je zadovoljstvo putnika. U ovom radu se analiziraju postojeća savremena tehnološka rešenja koja se primenjuju na aerodromima širom sveta i analizira njihov uticaj na zadovoljstvo putnika. Kroz sprovedeno istraživanje, analizira se stepen primene savremenih tehnoloških rešenja na aerodromu "Nikola Tesla", kao i zadovoljstvo putnika sa ponuđenim uslugama. Rezultati istraživanja pokazuju da aerodrom ide u korak sa svetskim rešenjima i da je visok stepan zadovoljstva putnika. Međutim, više od 50\% putnika i dalje koristi tradicionalne usluge, te se nova rešenja ne koriste u onoj meri u kojoj se očekivalo.
\end{abstract}

Ključne reči:

informacione tehnologije, turizam, avio industrija, zadovoljstvo putnika, avio tehnološka rešenja.

\section{UVOD}

Aerodromi predstavljaju ključnu tačku u putničkoj i turističkoj industriji jer povezuje avio kompanije, putnike i destinacije. Sve više stručnjaka smatra da će aerodromi u budućnosti imati sve karakteristike i funkcije jednog nezavisnog grada tzv. airport cities [1]. Aerodromi su se znatno razvili u poslednjih 30 godina, a sve te promene su bile direktno povezane sa tehnološkim razvojem [2].

Međunarodna asocijacija za vazdušni saobraćaj (IATA) predviđa da će u 2035. godine putovati 7,2 milijardi putnika, što je skoro dvostruko više u odnosu na 3,8 milijardi avio-putnika u 2016. godini [3]. Informacione tehnologije (IT) se primenjuju kroz sve procese i sektore koji čine aerodrom u celini, međutim ono što ima ključnu ulogu u domenu turizma su usluge koje se pružaju putnicima na aerodromima. Od tog prvog koraka tj. početka putovanja, umnogome zavisi zadovoljstvo putnika. Pružena usluga utiče na zadovoljstvo i iskustvo putnika, koji prolazi kroz više procesa aerodromskih usluga. Iz tih razloga, neophodno je da se razume uloga određenih tehnoloških rešenja na aerodromima i u kojoj meri utiču na zadovoljstvo putnika [4] [5].

Najnoviji IT trend koji prati aerodrome poslednjih godina, je svakako omogućavanje i postavljanje samouslužne tehnologije tokom svih koraka putovanja, kao što su bukiranje leta, prijava na let, pasoška kontrola, 
prijava prtljaga, vreme provedeno na aerodromu, ukrcavanje $\mathrm{u}$ avion, boravak $\mathrm{u}$ avionu i na kraju karusel za podizanje prtljaga nakon izlaska iz aviona [6-9]. Takođe važnu ulogu ima i zabava kroz virtuelnu realnost ili u vidu holograma i sl. [10]. Cilj je modernizacija infrastrukture aerodroma i digitalizacija procesa kroz koje putnici prolaze od trenutka dolaska na aerodrom, pa sve do izlaska iz aviona, kako bi se povećalo zadovoljstvo i iskustvo putnika. Iako i dalje postoje putnici koji radije koriste „licem u lice" usluge, sve je veći procenat putnika koji koriste informacione, posebno mobilne tehnologije za obavljanje tih procesa, kao na primer za brže i efikasnije dolaženje do informacija, rezervisanje karata, prijavljivanje na let, sigurnije praćenje svog prtljaga, više zabave tokom leta i slično. U prilog ovome govori i nedavno sprovedeno istraživanje od strane SITA i Air Transport World organizacije [11], koje je obuhvatilo 17 zemalja širom Amerike, Evrope, Azije, Afrike i Bliskog Istoka, tokom 2017. godine. Putnici koji su putovali, bar jednom u prethodna tri meseca, kroz neki regionalni anketirani aerodrom, ocenili su svoje zadovoljstvo na svakom koraku putovanja. Rezultati prikazuju da su „tehnološki“ korisnici zadovoljniji sa iskustvom tokom putovanja od onih koji koriste usluge „licem u lice“. Jednostavne za korišćenje tehnološke usluge, mogu ukloniti složenost i pojednostaviti putovanje, što povećava zadovoljstvo putnika.

Mnogi autori su se bavili istraživanjima o primeni savremenih informacionih tehnologija i njihovom uticaju na avio-saobraćaj u celini, sa posebnim osvrtom na razvoj i upotrebu informacionih tehnologija za poslovanje aerodroma i avio-kompanija, kao bitne činioce za razvoj turizma i poboljšanje satisfakcije turista, odnosno putnika. Drennen [12] je analizom samouslužnih tehnologija na aerodromima ukazao na njihov vitalan značaj za poslovanje i zadovoljstvo putnika. Jaffer et al. [13] ukazali su na značaj digitalne strategije na aerodromima u cilju poboljšanja kvaliteta usluga tokom putovanja putnika. Milićević
[14] je ukazao na ulogu i značaj inovacija u avio industriji u cilju zadovoljenja potreba potrošača, ali i njihovog uticaja na lojalnost putnika. Harteveldt [15] predviđa budući razvoj tehnologija u domenu avio industrija kroz sve veću ulogu Google servisa u distribuciji usluga avio kompanija, čime će se znatno povećati prodaja.

U ovom radu se, na osnovu analize savremenih tehnoloških rešenja za pružanje usluga putnicima na aerodromima, sagledava nivo implementacije postojećih rešenja na međunarodnom aerodromu "Nikola Tesla“ Beograd, kao i stepen zadovoljstva putnika e-uslugama koje su dostupne na aerodromu „Nikola Tesla“.

\section{PRIMENA SAVREMENIH TEHNOLOŠKIH REŠENJA NA AERODROMIMA}

Za većinu putnika teško je zamisliti putovanje bez pametnog telefona, laptopa ili eventualno pametnog sata. Mobilni uređaji su nezaobilazni putni alat koji pomažu u upravljanju koracima putovanja, informišući putnike i zabavljajući ih. Oko 70\% putnika nosi sa sobom više od dva uređaja tokom putovanja, a skoro većina (98\%) imaju najmanje jedan. Putnici koji su koristili samouslužne tehnologije, bilo na vlastitim uređajima ili preko aerodromskih objekata, za procesiranje bilo kojeg stepena putovanja, prijavili su više nivoe zadovoljstva nego korisnici koji ih ne koriste. Ova razlika je naročito bila izražena u tri faze: tokom boravka na aerodromu kada su uživali u aerodromskim sadržajima, tokom leta i dok su čekali na karuselu za njihov prtljag. Rezultati sprovedene ankete (Slika 1) pokazuju da putnici ocenjuju svoje putovanje vrlo visoko sa ukupnom stopom zadovoljstva od 8,2 do 10 , ali se to još više podstiče kada se koriste tehnologije poput mobilnih usluga i biometrije. Sposobnost usmeravanja i ubrzanja procesa putovanja ili poboljšanja iskustva putnika dovešće do korišćenja tehnologije samousluživanja na budućim putovanjima.

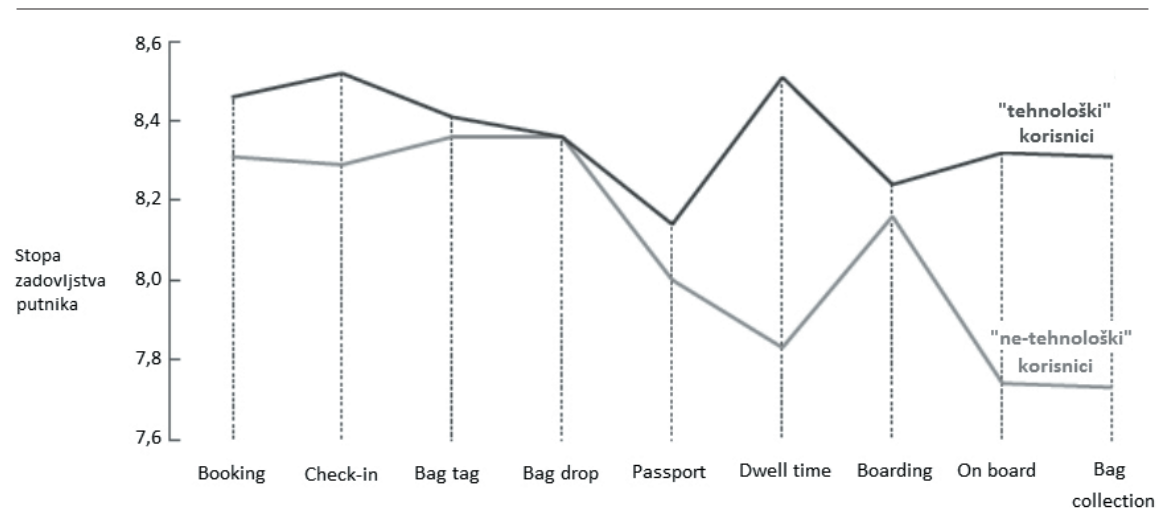

Slika 1. Zadovoljstvo „tehnoloških“ i „netehnoloških“ korisnika [12] 
U daljem tekstu se navode aktuelna tehnološka rešenja koja se primenjuju na aerodromima širom sveta, kao i stepen zadovoljstva putnika tim uslugama [12].

Tehnologija za bolje rezervisanje (booking) i prijavu na let (check in). Putnici uglavnom već koriste neke web aplikacije za istraživanje, rezervisanje i pripremu za putovanje, te su oni danas otvoreniji za korišćenje novih e-usluga na aerodromima. Većina putnika (skoro 90\%) rezervisala je svoje poslednje putovanje korišćenjem samouslužnih tehnologija. Više od $50 \%$ putnika je koristilo samousluživanje za prijavu na let, putem web-a ili popularnih check-in kioska. Bilo koji metod da su koristili stepen zadovoljstva sa svojim check-in iskustvom je bio veoma visok.

Tehnologija za bolje označavanje prtljaga (bag tag) Putnicima je omogućeno da sami kreiraju i odštampaju sopstvenu oznaku za prtljag, kao deo procesa prijavljivanja na let. Ovu uslugu uglavnom (47\%) koriste mlađi putnici (između 25 i 45 godina), što je povećanje za 31\% od 2016. godine.

Tehnologija za bolje predavanje prtljaga (bag drop) - Najnovije stanice za samouslužno predavanje prtljaga automatski detektuju i skeniraju oznake na prtljagu i otpremaju prtljag u sistem. Iako su putnici spremni da sami označe svoje torbe, većina nastavlja da predaje svoj prtljag uz pomoć agenta. Upotreba ove usluge se sporo smanjuje (sa $85 \%$ u 2016. godini na $82 \%$ ). Gotovo petina (18\%) koristi ovaj autoservis predavanja prtljaga (porast od $14 \%$ u odnosu na prošlu godinu). Ove stanice nisu trenutno dostupne na svim aerdoromima.

Tehnologija za bolje preuzimanje prtljaga (baggage claim) - Iako je 90\% putnika ocenilo da je zadovoljno sa iskustvom ukrcavanja u avion, najlošije je ocenjen korak preuzimanja prtljaga. Međutim, tehnologija pomaže u oslobađanju anksioznosti čekanja na prtljag, aktivnim pružanjem informacija o prikupljanju prtljaga putnika. Više od polovine (58\%) putnika, koji su čekirali svoj prtljag, 22\% je koristilo mobilnu aplikaciju za praćenje kretanja svog prtljaga u realnom vremenu, što je poboljšalo nivo zadovoljstva ovom uslugom za dodatnih $10 \%$.

Tehnologije za automatizovanu pasošku kontrolu (ID control) - Pasoška kontrola ima jednu od najnižih ocena zadovoljstva putnika. Tehnologije i samouslužna rešenja koja se koriste za automatizovanu kontrolu pasoša iskoristilo je 37\% putnika na poslednjem putovanju. Većina ovih putnika je koristila ovu vrstu tehnologije prilikom odlaska, ulaska na gejtove i kod međunarodnih dolazaka. Ova tehnologija je omogućila uključivanje putnika u kontroli pasoša, a time se ublažila neizvesnost sa agentima ili zaglavljivanje u sporijim redovima. Putnici koji koriste automatizovanu ID kontrolu imaju bolje iskustvo nego oni koji koriste kontrolu licem u lice. Biometrijska rešenja za pojednostavljivanje i ubrzavanje ID provere verovatno će se pojaviti i u drugim fazama putovanja na aerodromima. Avio kompanije i aerodromi već testiraju prepoznavanje lica na stanicama za predavanje prtljaga i na ukrcavanju.

Personalizovane mobilne aplikacije - Avio kompanije i aerodromi inoviraju svoje usluge za podršku putnicima ugrađujući elemente veštačke inteligencije u svoje mobilne aplikacije. IoT (Internt of Things) tehnologije, koji na osnovu generisanih podataka od senzora raspoređenih po aerodromima, omogućavaju pružanje mapa radi pronalaženja mesta za čekiranje, gejta za odlazak, najbližeg restorana ili slanja upozorenja bazirana na trenutnoj lokaciji putnika. Ove inicijative imaju za cilj da pruže personalizovane informacije $i$ usluge, $u$ realnom vremenu, koje podržavaju putovanje tokom boravka na aerodromu, u avionu i dolaska na odredišni aerodrom. Pojedine aplikacije omogućavaju da putnici unapred naruče obroke, preuzmu časopise, informišu se o svom letu, putu do izlaza (gejta), prilagode lični prostor u kabini aviona, poruče kafu da ih čeka u salonu avio kompanije i dr. Nekoliko avionskih aplikacija već omogućavaju putnicima da prate svoje torbe u realnom vremenu tokom čitavog putovanja. Rezolucija $753 \mathrm{Me}-$ đunarodnog udruženja za vazdušni saobraćaj (IATA) će zahtevati od svojih članica avio kompanija da prate svaku stavku prtljaga od početka do kraja putovanja, od juna 2018. U budućnosti se može očekivati da će mnoge avio kompanije nuditi aplikacije za praćenje prtljaga putem prtljažnih privezaka.

Tehnologija za bolju povezanost na aerodromima (dwell time) - Restorani, barovi i kupovina ostaju tradicionalni načini za uživanje, u slobodno vreme, na aerodromima. Međutim, tehnologija je postala jednako važna u vremenu provedenog na aerodromu pre poletanja. Jedan osnovni uslov za putnike koji nose pametne uređaje je pristup internetu. Kada je dostupan, WIFI je najkorišćenija usluga. Sposobnost odmaranja i punjenja baterija (mentalnih, kao i elektronskih uređaja) je još jedna ključna želja putnika. Nanoviji razvoj je uvođenje "kapuljača" tihih stolica koje smanjuju ambijentalnu buku za osobu koja sedi unutra. Obično ima utičnicu za napajanje, USB port i integrisane zvučnike, omogućavajući korisnicima da reprodukuju muziku sa svog vlastitog uređaja.

Tehnologija za bolju povezanost u vazduhu (on board) - Bez obzira da li putnici gledaju film, šalju e-mail ili su u kontaktu sa porodicom i prijateljima preko društvenih 
mreža, neke avio kompanije pružaju mogućnost naručivanja hrane i pića preko ekrana sedišta. Nešto za piće ili jelo su glavni prioriteti za putnike tokom leta, nakon čega ide zabava kao što su filmovi, muzika, igre ili novosti. Do sada, avio kompanije su opremale svoju posadu pametnim telefonima ili tabletima kako bi pružili personalizovane informacije i usluge putnicima, kao npr. rezervacija taksija tokom leta.

\section{ISTRAŽIVANJE O UPOTREBI INFORMACIONIH TEHNOLOGIJA NA AERODROMU "NIKOLA TESLA" BEOGRAD}

\section{Analiza poslovanja Aerodroma „Nikola Tesla“ Beograd}

Aerodrom Beograd počinje sa radom još od 1910. godine, kada je letilište na Banjici bilo prvi beogradski aerodrom. Aerodrom se vremenom razvijao, unapredivao i menjao svoje lokacije. Od 2006. godine, postojećem imenu je dodat naziv „Nikola Tesla“. Aerodrom kao akcionarsko društvo postaje sredinom juna 2010. godine. Beogradski međunarodni aerodrom se danas nalazi u Surčinu, 18 kilometara od centra grada. Cilj unapređenja poslovanja Aerodroma „Nikola Tesla“ Beograd je podizanje nivoa usluga putnicima na jedan viši nivo. Menadžment aerodroma kontinuirano radi na poboljšanju tehničko-tehnoloških performansi, povećanju broja putnika, unapređenju usluga i postizanju totalne satisfakcije korisnika i stejkholdera.

Razvoj unapređenja poslovanja i infrastrukture aerodroma

Vizija Vlade Srbije je da zemlja postane tranzitno čvorište regiona i prvi izbor investitora koji žele da ulažu u ovaj deo Evrope. Kroz Aerodrom u 2016. prošlo je 4,92 miliona putnika, gotovo 1,4 miliona putnika više nego pre tri godine. Trend rasta nastavljen je i tokom 2017. godine. Kako bi beogradski aerodrom mogao da prati rast broja putnika i uvođenje novih linija, uz podršku Vlade Srbije, uloženo je oko četiri milijarde dinara za prethodne dve i po godine u modernizaciju, proširenje kapaciteta i podizanje kvaliteta usluge. Deo tog investicionog ciklusa je i rekonstrukcija Terminala 1, kojom je kapacitet Aerodroma povećan sa pet na sedam miliona putnika godišnje. Rast broja putnika beogradskog aerodroma direktno je povezan i sa dobrim poslovnim rezultatima nacionalnog avio-prevoznika „Air Srbije“, koji je tokom 2016. godine prevezao 2,62 miliona putnika [16]. Plan je i da aerodrom, poput mnogih u Evropi i svetu, postane svojevrsna turistička tačka.

\section{Upotreba savremenih tehnologija na aerodromu}

Veb sajt aerodroma „Nikola Tesla“ pruža sve neophodne informacije putnicima, kao što su: red letenja, veb check-in, informacije o avio-kompanijama, mapu aerodroma, važne informacije u vezi sa njihovim putovanjima ili izmenama na aerodromu i sl. Aerodrom se oglašava i preko društvenih medija, kao što su Facebook, Twitter, Instagram i Youtube. Razvijena je i zvanična mobilna aplikacija za Android, Windows i iOS platforme. Ova aplikacija pruža sve neophodne informacije u vezi sa boravkom na aerodromu i uslugama koje pruža. Opcije koje sadrži su:

- Letovi - primarna funkcija koja u realnom vremenu daje najaktuelnije informacije o statusu određenog leta: broj leta, destinacija, planirano i očekivano vreme i izlaz.

- Sa i do aerodroma - sve informacije o tome kako se može stići do aerodroma i gde se može parkirati vozilo. Direktno iz aplikacije može se ostvariti poziv ka rent-a-car agenciji.

- Radno vreme na aerodromu - veliki broj prodavnica, restorana i barova je na raspolaganju putnicima.

- Mapa aerodroma - mapa može pomoći u lociranju položaja putnika u odnosu na odredište, restoran, prodavnicu ili izlaz.

- Avio-kompanije - u odeljku „Web check-in“ aplikacija direktno vodi na stranicu za prijavu na let izabranog avio-prevoznika.

Putnicima je omogućena prijava na let, na nekoliko načina:

- Prijava putem veb sajta - u posebnom delu za onlajn prijavu na let, putnici mogu pronaći linkove za svaku avio-kompaniju posebno, koja ih direktno vodi ka izvršenju prijave. Kada se onlajn prijava završi, na e-mail se šalje elektronska karta za ukrcavanje (boarding pass).

- Prijava na kiosku - Aerodrom Nikola Tesla Beograd pruža mogućnost prijave na let uz pomoć samostalnih kioska, koji se nalaze na Terminalu 1 i 2.

- Prijava putem mobilne aplikacije - omogućava pristup web strani ili aplikaciji određene aviokompanije gde u okviru za samostalno prijavljivanje na let (mobile check-in), putnik može da se prijavi na let. Nakon prijave, putniku se šalje karta za ukrcavanje prikazane u vidu dvodimenzionalnog koda (QR code). 
- Bežični internet (WLAN, WIFI) - ova vrsta servisa je stalno dostupna i obuhvata sledeće površine aerodroma: autobusko stajalište, oba terminala, tranzitnu zonu, salone, gejtove, check in šaltere, čekaonice, sve hodnike i prostorije aerodroma.

Aerodrom „Nikola Tesla“ Beograd, pored e-usluga, svojim putnicima nudi i dodatne usluge, kao što su: komforne zone, prodavnice, restorani, barovi, turističke informacije, medicinska nega, parking servis, prostorije za decu, aerodromski saloni i slično.

\section{ANALIZA REZULTATA ISTRAŽIVANJA O ZADOVOLJSTVU PUTNIKA E-USLUGAMA AERODROMA „NIKOLA TESLA“ BEOGRAD}

\section{Opis istraživanja}

Rezultati istraživanja zadovoljstvom usluga i tehnologija na Aerodromu „Nikola Tesla“ Beograd (NTB) prikazani su na osnovu istraživanja koje je izvršeno u periodu od sredine jula do početka septembra 2017. godine. Istraživanje je izvršeno tehnikom anketiranja, a instrument je bio upitnik, koji je kreiran pomoću Google Forms-a. Njime su prikupljeni neophodni podaci u vezi sa zadovoljstvom usluga i upotrebom tehnologija od strane putnika na Aerodromu.

U anketi je učestvovalo 100 ispitanika, odnosno putnika, koji su koristili usluge NTB-a. Anketa se sastojala od 20 pitanja. Prvi deo ankete se odnosio na ocenu stepena zadovoljstva uslugama na aerodromu, uglavnom kroz uslužne procese, dok se drugi deo odnosio na implementaciju informacionih tehnologija za poboljšanje iskustva putnika.

\section{Rezultati istraživanja}

Najveći broj putnika je koristio usluge aerodroma NTB u 2017. godini - 55\% ispitanika, zatim slede putnici iz 2016. godine - $28 \%$ ispitanika, 2015. godine - $8 \%$ ispitanika, 2014. godine - 6\% ispitanika, 2013. godine - $2 \%$ ispitanika. Najmanji broj putnika je iz 2011. godine - 1\% ispitanika. Najčešća svrha posete aerodroma NTB je dolazak i dolazak - 48\% ispitanika, odlazak - 33\% ispitanika, dolazak - $14 \%$, a najmanje je bilo putnika čija je svrha bila isključivo tranzitiranje kroz aerodrom - $5 \%$ ispitanika. Tipovi putnika koji najmanje koriste usluge ovog aerodroma su poslovni putnici - 9\% ispitanika, zatim solo putnici $18 \%$ ispitanika, porodični putnici - $18 \%$ ispitanika, putnici u paru - 22\%, dok se najveći broj ispitanika opredelio za odgovor: zavisi od vrste i razloga putovanja - 33\%.

\section{Zadovoljstvo putnika}

\begin{tabular}{|c|c|c|c|c|c|}
\hline \multirow[t]{2}{*}{ Usluge } & \multicolumn{5}{|c|}{ (u skali od 1-5) } \\
\hline & 1 & 2 & 3 & 4 & 5 \\
\hline $\begin{array}{l}\text { Lokacijska dostupnost } \\
\text { aerodroma }\end{array}$ & 9 & 9 & 26 & 26 & 27 \\
\hline Dostupnost informacija & 8 & 8 & 25 & 33 & 20 \\
\hline Vreme čekanja & 9 & 15 & 25 & 32 & 18 \\
\hline $\begin{array}{l}\text { Čistoća terminala i } \\
\text { ostalih prostorija }\end{array}$ & 14 & 15 & 24 & 17 & 29 \\
\hline Komfor pri čekanju & 7 & 14 & 32 & 27 & 19 \\
\hline $\begin{array}{l}\text { Izbor hrane/pića/ } \\
\text { kupovine }\end{array}$ & 7 & 17 & 34 & 21 & 21 \\
\hline Usluge Wifi-a & 9 & 14 & 17 & 34 & 25 \\
\hline $\begin{array}{l}\text { Bezbednosne provere i } \\
\text { osećaj sigurnosti }\end{array}$ & 11 & 11 & 14 & 27 & 32 \\
\hline $\begin{array}{l}\text { Ljubaznost zaposlenog } \\
\text { osoblja }\end{array}$ & 8 & 6 & 18 & 30 & 35 \\
\hline Izbor avio kompanija & 7 & 9 & 29 & 30 & 22 \\
\hline
\end{tabular}

Tabela 1. Ocena stepena zadovoljstva uslugama koje pruža aerodrom NTB

Tabela 1 prikazuje detaljne ocene koje su putnici dolelili navedenim aerodromskim uslugama. Najvišu ocenu 5, putnici su dali: lokacijskoj dostupnosti aerodroma, čistoći terminala i ostalih prostorija, bezbednosnim proverama i osećaju sigurnosti i na kraju ljubaznosti zaposlenog osoblja. Usluge ocenjene sa 4 su: dostupnost informacija, vreme čekanja, usluge Wifi-a i izbor avio-kompanija. Kao najlošije ocenjene usluge su: komfort pri čekanju i izbor hrane i pića.

Aerodrom NTB pruža mnogobrojne usluge svojim putnicima, kako uslužne tako i elektronske. Usluga koja se koristi najviše je Internet (58\% ispitanika), dok se za medicinsku nego nije opredelio ni jedan ispitanik. Nakon Interneta, najviše se koriste i restorani i barovi (47\%), zatim kupovina (35\%), parking servis (30\%) i dalje se nadovezuju turističke informacije, komforne zone, aerodromski saloni, prostorije za decu, novčane usluge i osiguranje, i na kraju informacije o smeštaju u Beogradu, koje zapravo najčešće koriste strani putnici. Korisnici su Aerodrom NTB ocenili sa ocenom 4 (47\% ispitanika). Više od polovine putnika koji su koristili usluge aerodroma NTB reklo je da bi preporučilo ovaj aerodrom (81\%), što je odlična preporuka. Kada su u pitanju web izvori aerodroma NTB, među putnicima najpopularniji za pretragu informacija o aerodromskim uslugama je web sajt (51\% ispitanik), aplikacija za mobilne uređaje (14\%), 
društvene mreže (13\%), dok se $11 \%$ ispitanika i dalje služi telefonom na tradicionalan način i uopšte ne koristi web izvore. Većina putnika koja je koristila internet servise aerodroma NTB ocenila je da je potpuno zadovoljna izgledom i tačnošću informacija koje se pružaju putem određenih Internet servisa aerodroma NTB, dok se 15\% ispitanika opredelilo za to da ne koriste internet servise, a $13 \%$ ispitanika da nije zadovoljno.

Aerodrom NTB je nedavno kreirao svoje profile na društvenim medijima. Informacije i postovi se redovno ažuriraju. Na društvenim mrežama se može pronaći spektar informacija i postova koji mogu poslužiti putnicima u svrhu informisanja o uslugama, ocenjivanja zadovoljstva uslugama, komunikacije sa zaposlenima, kao i u svrhu razonode i pregleda postova. U prilog ovome govore sledeći rezultati: $31 \%$ putnika koristi društvene mreže u svrhu informisanja, $14 \%$ u svrhu pregleda i postavljanja postova, a samo $2 \%$ ocenjuje zadovoljstvo uslugama preko društvenih mreža. Korisnici usluga aerodroma NTB odgovorili su da ocenjuju i dele iskustva o uslugama samo sa užim krugom ljudi (43\%), dok 15\% ispitanika dele svoja iskustva na Internetu.

Stepen korišćenja Bilten liste aerodroma NTB za pružanje novih informacija nije visok - $86 \%$ ispitanika je reklo da ne koristi bilten listu, a iz prethodnih odgovara se može zaključiti da su putnici aerodroma NTB više okrenuti ka web izvorima i servisima, iz razloga što brzo i efikasno mogu doći do svih neophodnih informacija, kada su im i potrebne.

Aplikacija za mobilne uređaje aerodroma NTB pruža brojne prednosti putnicima, međutim stepen njenih korišćenja je mali. Čak $45 \%$ putnika ne koristi mobilnu aplikaciju aerodroma NTB, 35\% koristi u svrhu informisanja o redu letenja, $9 \%$ za informacije o avio-kompanijama, 5\% za informacije kako do i od aerodroma, 3\% za mapu aerodroma i 3\% za informacije o tome kako da provedu slobodno vreme dok čekaju. Razlog slabe posećenosti aplikacije, može biti i njenoj slaboj promociji i upoznavanja putnika sa njenim mogućnostima.

Danas je nezamislivo da aerodrom bilo gde u svetu, ne pruža mogućnost povezivanja sa Internetom za svoje putnike. Wifi Internet je dostupan i besplatan u celoj aerodromskoj zgradi NTB, na koji se putnici lako mogu prijaviti. Samo 10\% putnika je odgovorilo da ne koristi Wifi na aerodromu. Putnici koriste Internet $\mathrm{u}$ razne svrhe, $7 \%$ u poslovne svrhe, $46 \%$ za razonodu, a $36 \%$ i za posao i za razonodu. Sa razvojem tehnologije na aerodromima, razvile su se mogućnosti i načini da se putnici samostalno prijave na let, u cilju brže, efikasnije, sigurnije usluge i kako bi se smanjila čekanja u redovima i povećala satisfakcija uslugama. Na pitanje na koji se način najčešće čekiraju, putnici su odgovorili sledeće: šalter (64\% ispitanika), putem interneta (23\%), kiosk za samostalno čekiranje i predaju prtljaga (10\%), mobilni uređaj (3\%).

Putnicima aerodroma NTB je postavljeno pitanje da izaberu koja bi tehnološka rešenja voleli da koriste i vide na aerodromu NTB. Ponuđeni odgovori predstavljaju tehnološka rešenja koja se primenjuju na razvijenijim aerodromima širom sveta, a srpski putnici su se opredelili za sledeća: automatizovana pasoška kontrola ( $24 \%$ ispitanika), aplikacije za samostalno praćenje lokacije prtljaga u realnom vremenu (23\%), samostalna predaja i obeležavanje prtljaga (13\%), komforne zone sa elektronskim kioscima za samostalno usluživanja i odmor (13\%), dok se $15 \%$ ispitanika opredelilo za to, da im nije važno koja će se tehnološka rešenja naći na aerodromu iz razloga što se oni više opredeljuju za uslužne procese u odnosu na elektronske.

Prednosti koje donose tehnološka rešenja, putnici aerodroma NTB vide u sledećem: efikasnije i brže usluge (46\%), smanjenje čekanja u redovima (27\%), manje stresa tokom putovanja (19\%), slobodno organizovanje svih koraka putovanja (8\%). Pored brojnih prednosti tehnologija ipak ima i neke negativne strane. Najviše ocenjen kao nedostatak ovakvog vida korišćenja tehnologija je to što nema direktnog kontakta sa osobljem (40\%), zatim slabo znanje korišćenja tehnologija (30\%), nepoverenje u tehnologiju (19\%) i loša iskustva (11\%). Nemanje direktnog kontakta sa osobljem može predstavljati veliki nedostatak, iz razloga što, zaposleni uliva više poverenja nego tehnologija.

\section{ZAKLJUČAK}

Analizom upotrebe postojećih tehnoloških rešenja koja se koriste na razvijenijim aerodromima u svetu, ukazuje na povećanje zadovoljstva putnika aerodromskim uslugama, u odnosu na prethodne godine. Dugi redovi za čekiranje, stres tokom prolaska kroz pasošku kontrolu, traženje gejtova, čekanje na prtljag i strepnja da se ne izgubi, kao i druge negativne emocije tokom puta avionom, znatno su smanjene sa upotrebom savremenih tehnoloških rešenja. Savremeni putnik je danas, upoznatiji sa aerodromskim procesima, kroz dostupne aplikacije i tehnologije, koje mu omogućavaju da i sam bude deo tih procesa, upotrebom samouslužnih sistema. Implementacijom veštačke inteligencije u postojeće sisteme, omogućena je personalizovanija usluga putnicima u cilju povećanja zadovoljstva putnika. 
Nacionalni međunarodni aerodrom „Nikola Tesla“ Beograd, ostvaruje znatan profit od putnika, te i sam ulaže u poboljšanje infrastrukture i postojećih usluga. Proširivanjem postojećih kapaciteta u mogućnosti je da primi više putnika, a primenom savremenih tehnoloških rešenja, teži da bude u rangu sa razvijenim aerodromima, kako bi putnicima pružio još veće zadovoljstvo tokom korišćenja aerodromskih usluga. U ovom radu, kroz sprovedeno istraživanje, analizirao se odnos primene savremenih rešenja na aerodromu NTB i zadovoljstva putnika. Rezultati ukazuju da iako je aerodrom NTB omogućio putnicima savremena tehnološka rešenja, gde se čak $95 \%$ putnika izjasnilo da aerodrom treba da ulaže u savremene tehnologije, ta rešenja se i dalje ne koriste u onoj meri koliko se očekuje. Na primer, za check-in, više od pola se i dalje opredeljuje za uslužan način prijave na let, odnosno za check-in na šalteru.

\section{LITERATURA}

[1] Setiawan, M., Surjokusumo, S., Ma'some, D.M., Johan, J., Hasyim, C., Kurniasih, N., Sukoco, A., Dhaniarti, I., Suyono, J., Sudapet, I.N., Nasihien, R.D., Mudjanarko, S.W., Wulandari, A., Ahmar, A.S., Wajdi, M.B.N. (2018) Business Centre Development Model of Airport Area in Supporting Airport Sustainability in Indonesia. Journal of Physics: Conference Series, Vol. 954, No. 1, pp: 012024 (Available at: http://stacks.iop.org/1742-6596/954/ $\mathrm{i}=1 / \mathrm{a}=012024$.

[2] Gheorghe, C.M., Stoenescu, C. (2015) Information Technology - A Tool To Redefine The Air Travel Essentials. Romanian Economic Business Review, Romanian-American University, vol. 10(2), pages 155-166, June.

[3] Buhalis, D. (2003) eAirlines: Strategic and tactical use of ICTs in the airline industry, University of Surrey, UK.

[4] Drennen, H. (2011) Self Service Technology in Airports and the Customer Experience, University of Nevada, Las Vegas.

[5] Gretzel, U., Sigala, M., Xiang, Z., Koo, C. (2015) Smart tourism: foundations and developments, Electronic markets, The International Journal on Networked Business, September 2015, Vol. 25, Issue 3, pp 179-188.
[6] Harteveldt, H.H. (2016) The Future of Airline Distribution, Atmosphere Research Group, IATA.

[7] Jaffer, S., Timbrell, G. (2014) Digital Strategy in Airports, Australasian Conference on Informations Systems, New Zeland.

[8] Milićević, S. (2016) Inovativnost u funkciji rasta i razvoja turističke industrije na turističkom tržištu, Univerzitet u Kragujevcu, Megatrend revija, Vol. 13, No. 1, 2016: 147-158.

[9] Njeguš, A., Jovanović, V., Veinović, M. (2015) Izazovi i mogućnosti primene analitike velikih podataka u hotelskom poslovanju, X međunarodni naučno stručni simpozijum "Hotelska kuća", HORES, Zlatibor.

[10] Song, H., Liu, H. (2017) Predicting Tourist Demand Using Big Data, Springer International Publishing, Switzerland.

[11] Vidyullata, S. (2011) Information Technology in Tourism, International Journal of Computer Science and Information Technologies, Vol. 2 (6) , 2011, 2822-2825.

[12] SITA (2017) Air Transport Industry Insights, Passenger IT Trend Survey, 27. June, 2017:1-18, dostupno na: http://www.sita.aero/.

[13] IATA (2018) 20 Year Passenger Forecast. Available at: http://www.iata.org/publications/store/ Pages/20-year-passenger-forecast.aspx (accessed: 27.03.2018).

[14] Hemdi, M.A., Rahman, S.A.S., Hanafiah, M.H. (2016) Airport self-service check-in: The influence of technology readiness on customer satisfaction. Heritage, Culture, and Society - Radzi et al. (Eds) Taylor \& Francis Group, London.

[15] Ivanov, S.H., Webster, C., Berezina, K. (2018) Adoption of Robots and Service Automation by Tourism and Hospitality Companies. Revista Turismo \& Desenvolvimento, 27/28, 1501-1517.

[16] Terminal, Magazin Aerodroma Nikola Tesla Beograd, broj 1, april-jun 2017,dostupno:http://www. beg.aero/strana/26131/D0 A7 D0 B0 D1 81 D0 BE D0 BF D0 B8 D1 81.

[17] Terminal, Magazin Aerodroma Nikola Tesla Beograd, broj 2, jul-septembar 2017,dostupno:http:// www.beg.aero/strana/26131/ D0 A7 D0 B0 D1 81 D0 BE D0 BF D0 B8 D1 81. 